\title{
A DISTRIBUIÇÃO GEOGRÁFICA DOS APORTES DO BNDES PARA A INDÚSTRIA DO PLÁSTICO, DA BORRACHA E DA QUÍMICA NO BRASIL
}

\author{
GEOGRAPHICAL DISTRIBUTION OF THE BNDES CONTRIBUTIONS \\ FOR PLASTIC INDUSTRY, RUBBER AND CHEMISTRY IN BRAZIL
}

\section{LA DISTRIBUCIÓN GEOGRÁFICA DE LOS APORTES DE BNDES PARA LA INDUSTRIA DEL PLASTICO, DE LA GOMA Y DE LA QUÍMICA EN BRASIL}

\author{
Paulo Henrique Schlickmann - Universidade Federal de Santa \\ Catarina - Florianópolis - Santa Catarina - Brasil \\ p.h.schlickmann@ufsc.br
}

\begin{abstract}
Resumo
Nos últimos 13 anos, a economia brasileira vivenciou um período de euforia com 0 que se convencionou chamar de "o sucesso das políticas nacionais desenvolvimentistas aplicadas pelo governo petista" (2003 - 2016). 0 Banco Nacional do Desenvolvimento Econômico e Social (BNDES) desempenhou um importante papel no desdobramento dessas políticas através de aportes financeiros a diversos grupos empresariais. 0 objetivo deste artigo é apresentar detalhadamente as características dos aportes financeiros destinados à indústria do plástico e da borracha e à indústria química brasileira. Primeiramente, são apresentados os dados gerais levantados do portal Transparência BNDES. Posteriormente, esses dados são especificados por gênero industrial, empresa, localização e objetivo dos projetos demandantes. Observou-se uma aparente conexão entre a disponibilização dos recursos e as empresas denominadas "campeãs nacionais". Finalmente, lançamse algumas questões referentes a esse modelo de financiamento.
\end{abstract}

Palavras-chave: desenvolvimento, financiamento, política econômica, Geografia Econômica.

\section{Abstract}

For the past 13 years, the Brazilian economy experienced a period of euphoria with the so-called "success of the national development policies implemented by the Partido dos Trabalhadores (PT) Government" (2003 - 2016). The Banco Nacional do Desenvolvimento (BNDES) played an important role in the unfolding of these policies through financial contributions to various business groups. The objective of this paper is to present in detail the characteristics of financial contributions for the plastic and rubber industry as well as for the Brazilian chemical industry. Firstly, the general data raised by the BNDES Transparency portal are presented. Subsequently, these data are specified by industrial category, company, location and purposes of the demanding projects. An apparent connection was observed between the availability of resources and the companies called "national champions". Finally, some questions regarding this funding model are posed. Keywords: development, financing, economic policy, Economic Geography.

\section{Resumen}

Durante los últimos 13 años, la economía brasileña experimentó un período de euforia con lo que se acordó en llamar "éxito de las políticas nacionales de desarrollo implementadas por el gobierno del PT" (2003 - 2016). El Banco Nacional de Desarrollo Económico y Social (BNDES) jugó un papel importante en el desarrollo de esas políticas a través de contribuciones financieras a los diversos grupos empresariales. El propósito de este trabajo es dar a conocer en detalle las características de las contribuciones financieras destinados a la industria del caucho y del plástico, así como para la industria química brasileña. En primer lugar, se presentan los datos generales planteados por el portal de transparencia del BNDES. Posteriormente, estos datos son 
especificados por categoría industrial, empresa, ubicación y propósitos de los proyectos demandantes. Se observó una conexión evidente entre la disponibilidad de recursos y las empresas llamadas "campeonas nacionales". Finalmente se plantean algunas preguntas con respecto a ese modelo de financiación.

Palabras-clave: desarrollo, financiamiento, política económica, Geografía Económica.

Introdução

Uma das ideias pilares na mentalidade nacional desenvolvimentista é a execução de um matrimônio, ou pacto, entre as instituições financeiras, os atores políticos e as forças econômicas, preferencialmente originárias da nação em questão. Isso é observável nas defesas das ideias e posições clássicas de Keynes (1983), Rangel (1982), Bresser-Pereira (2015), entre inúmeros outros. Recentemente, no governo petista, Coutinho (2003; 2014) tornou-se líder na difusão desse ideal desenvolvimentista através do conceito-força popularmente difundido das "grandes campeãs nacionais"1.

Os desenvolvimentistas nacionalistas acreditam que: 1) devem atuar como agentes políticos na composição dos governos nacionais; 2) possuem a função racional e intelectual para compreender o todo da vontade nacional; e 3) necessitam estimular ou comandar os agentes e as instituições financeiras nacionais para que estas atuem como financiadoras dos agentes econômicos, sobretudo nos momentos das crises e recessões.

Na primeira ordem, como economistas que são, confiam no desenvolvimento econômico como a chave para se entender a história, portanto, para construir o futuro. Quando estudiosos da periferia do sistema, almejam através da intervenção, romper o atraso e superar as economias inferiores ou paritárias, no intuito de alcançar o centro econômico mundial. Sem dúvida, o desenvolvimentista é uma figura emblemática, pois sabe convictamente que é capaz de acumular funções complexas, intervir precisamente na sociedade e determinar a vida de milhares de indivíduos e classes sociais do país, quiçá do mundo.

Interessa que, ao longo do governo petista, iniciado em janeiro de 2003 e findado abruptamente em abril de 2016, foram 13 anos de mentalidade governamental nacional desenvolvimentista. Como se pôde acompanhar, ele englobou ao longo dos anos, nos mecanismos de poderes políticos, estatais e econômicos, uma miríade de boas e de más intenções, as quais não serão revisadas aqui. Pretende-se, neste artigo, apresentar um detalhamento dos aportes destinados pelo maior agente financeiro do Brasil para os agentes econômicos integrados à indústria do plástico, da borracha e da química, desde 2003. 
Primeiramente, serão lançados os dados gerais coletados na plataforma da transparência do BNDES (Brasil, 2016) ${ }^{2}$, com algumas descrições para sistematização das informações. No segundo momento, os dados serão apresentados por tipo de indústria: plástico e borracha, e química; e também expostos por gênero industrial: pneus, embalagens, construção civil, polímeros, agroquímicos e cosméticos, juntamente com a intensidade dos investimentos territorialmente alocados. Há, também, breve apresentação das justificativas das empresas privilegiadas.

Finalmente, serão expostas as considerações finais com o propósito de questionar a eficácia e a finalidade dos investimentos. Pretende-se lançar dúvidas sobre o ideário assumido como estratégico, contudo não explicado pelo BNDES (Almeida; Oliveira; Schneider, 2014), das campeãs nacionais nas indústrias dos "plásticos e borrachas" e da indústria "química”. Importa salientar que a motivação para o aprofundamento deste artigo surgiu quando iniciei a coleta dos dados para a elaboração da tese de doutoramento, cujo tema envolve a dinâmica geoeconômica das empresas localizadas no Brasil que sejam produtoras de embalagens plásticas inovadoras ${ }^{3}$.

\section{Os aportes do BNDES}

Como é de conhecimento público, através das campanhas dos partidos aliados e das propagandas do Governo, o volume de investimentos do BNDES foi um dos trunfos mais utilizados ao longo dos 13 anos de comando do Partido dos Trabalhadores (PT), como a justificativa de sucesso das suas políticas econômicas. Nitidamente, conforme a Figura 1 há uma ruptura na metade do primeiro mandato de Luiz Inácio Lula da Silva (Lula) em relação à quantidade de investimentos disponibilizada pelo banco durante a administração socialdemocrata (PSDB) de Fernando Henrique Cardoso (FHC) entre 1995 e 2002.

É importante ressaltar que, conforme Singer (2012) e Bresser-Pereira (2015), ambos foram governos socialdemocratas ${ }^{4}$. Poucas vezes é salientado, no entanto, que a mentalidade mais recente (2003-2016), além de desenvolvimentista, apresentou-se como nacionalista. A mentalidade anterior (1995-2002), igualmente desenvolvimentista, não se afirmava nacionalista. As raízes e as formas como esses dois pensamentos se colocam no tempo e no espaço reservam importantes conflitos entre as ações e a postura dos agentes ao longo da vida governamental, conforme se exibe na Figura 1. 


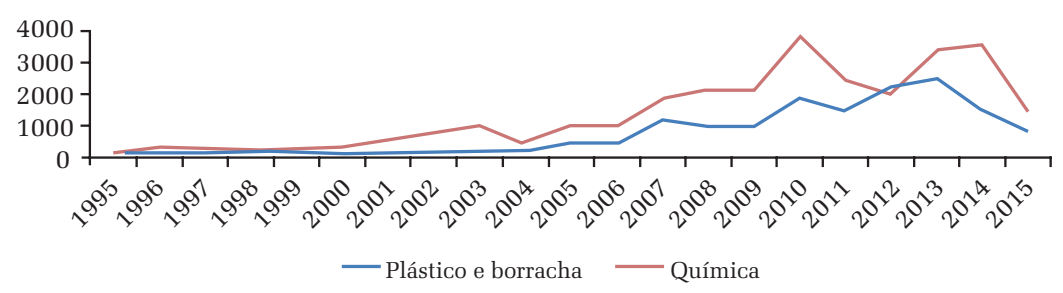

Figura 1 - Desembolsos, em milhões de reais do BNDES para a indústria do plástico e da borracha e para a indústria química entre 1995 e 2015 Fonte: Brasil (2016). Organização do autor.

Nota-se que na exposição da Figura $1^{5}$, para ambos os gêneros industriais, os investimentos iniciaram um processo de elevação a partir de 2004, apresentando-se crescentes até 2010, com leve queda em 2011, seguida de nova ascensão até 2014, quando os aportes caíram abruptamente. Se considerarmos os picos de alta em cada governo, entre 1995 e 2002 os subsídios para plásticos e borracha cresceram 3,25\%, enquanto entre 2003 e 2013 o crescimento foi na ordem de 878\%. A indústria química, porém, subiu $295 \%$ e $238,5 \%$,respectivamente.

A diferença para a indústria química é que o apoio do governo FHC ocorreu no fim de seu último mandato, em meio ao processo de privatizações do setor petroquímico, quando as investidas do BNDES eram direcionadas à compra de bens e equipamentos no exterior, investimentos na reestruturação empresarial e privatizações (Velasco Júnior, 2010). As atitudes da administração mais recente, como se percorrerá no próximo item, visavam aos incentivos para a modernização das unidades empresariais, para capital de giro ou para a instalação de novas plantas, numa reservada gama de empresas.

Na sequência, apresenta-se a Figura 2 com a porcentagem das contribuições, de acordo com o tamanho das empresas recebedoras para cada indústria. Nesse caso, é possível identificar as características particulares das indústrias estudadas. Isso, logo, independe da intenção do banco de investimento, sendo importante realçar que não houve, aparentemente, restrição por parte da instituição por conta do porte das empresas. Ao contrário, na indústria do plástico, 92\% das empresas empregam menos de 50 funcionários e, apesar do nível médio de intensidade tecnológica, o setor entrou como "prioritário” do governo em 2008, visto que em 2010 
o BNDES lançou o "plano de incentivo à cadeia do plástico", envolvendo os químicos, as borrachas e os ofertantes de insumos e equipamentos ${ }^{6}$.

Plástico e Borracha

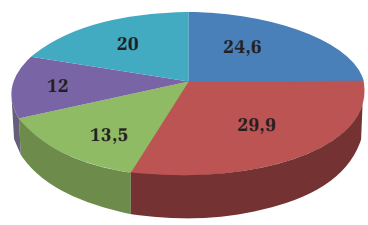

Química

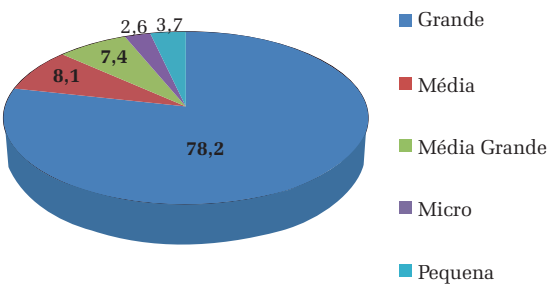

Figura 2 - Porcentagem do aporte de recursos do BNDES para a indústria do plástico e borracha e para a indústria química por porte das empresas entre 1995 e 2015 Fonte: Brasil (2016). Organização do autor.

A partir de 2002, é possível estabelecer uma discriminação nos investimentos aportados pelo banco. Os dados anteriores a essa data são indiretos e não se pretende estender a análise comparativa entre os governos. Por isso, é possível traçar um paralelo de divisão dos investimentos para a indústria do plástico e borracha por gênero industrial, conforme demonstram os dados da Figura 3. A centralização dos investimentos nas grandes empresas, em referência aos dados à esquerda na Figura 2, deve-se principalmente aos gêneros dos pneus e da construção civil, comandados por não mais de três tradicionais oligopólios internacionais ou nacionais. Os demais investimentos a essa indústria abarcam as pequenas e médias empresas.

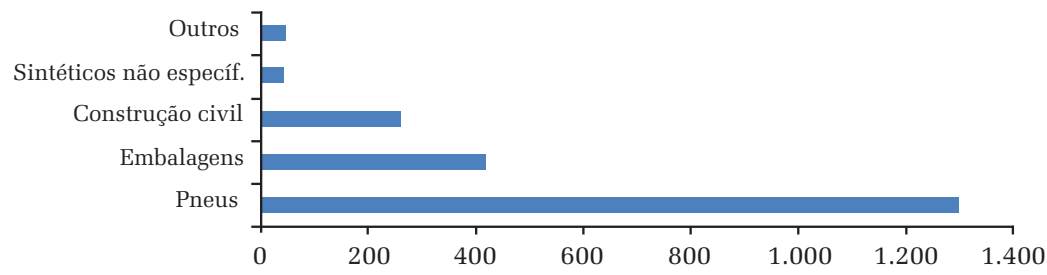

Figura 3 - Total de aporte do BNDES para a indústria de plástico e borracha por gênero industrial entre 2003 e 2015 (em mil reais) 
Ainda em relação à Figura 3, parece fundamental enfatizar que dentro da indústria do plástico e da borracha, o segmento das borrachas adquiriu quase $63 \%$ dos recursos, e desse total, praticamente $100 \%$ foram destinados ao gênero dos pneus, forte catalisador de financiamentos. Dentro do segmento dos plásticos, receptor de 37\% dos recursos, o gênero das embalagens auferiu 54,4\%, e o da construção civil 33,6\% dos expedientes. Portanto, percebe-se a centralização e a baixa fragmentação dos recursos entre os diversos gêneros dentro da mesma indústria.

Num julgamento resumido da Figura 3, é possível lançar mão de pelo menos dois argumentos-chave: A) manifesta-se uma centralização por parte do BNDES na disponibilização dos investimentos para um escasso número de gêneros inerentes à indústria especificada; e B) isso pode não se tratar de seletividade do banco, mas da demanda, e apenas os gêneros dinâmicos dentro de cada indústria acionam a agência de fomento do governo. Ambos os argumentos podem ser verdadeiros, entre outros possíveis, porém destaco esses com veemência.

Há algumas diferenças, no entanto, na organização da Figura 4, para o caso da indústria química, que é altamente monopolista em grandes grupos empresariais, conforme já se observou nos dados no lado direito da Figura 2. Com exceção do gênero de agroquímicos, cujo montante é racionado por aproximadamente 15 empresas, os demais se restringem a aportes decompostos por no máximo três empresas por gênero. Cabe pronunciar a participação do grupo Braskem, que dominou aproximadamente $52 \%$ de todo o recurso da indústria química, e por volta de $75 \%$ no gênero dos polímeros ${ }^{7}$.

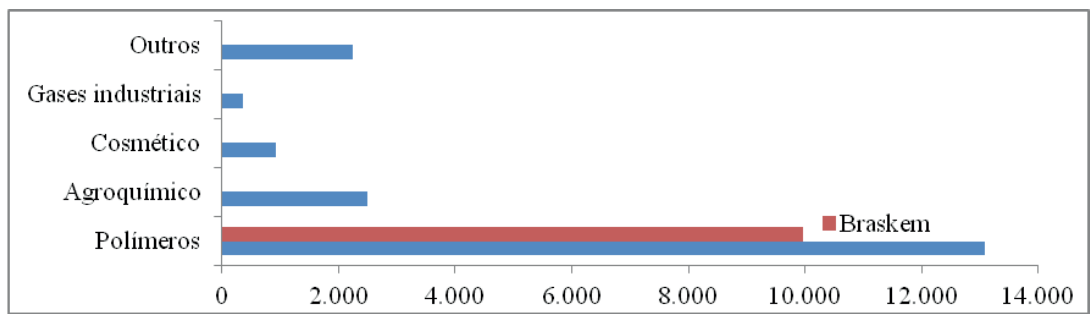

Figura 4 - Aporte do BNDES para a indústria química por gênero industrial entre 2003 e 2015 (em mil reais) Fonte: Brasil (2016). Organização e sistematização do autor. 
Em relação à distribuição de subsídios por gênero industrial, os polímeros receberam 68\% dos recursos dedicados aos químicos. Desse total, três quartos foram propostos para uma única empresa. O gênero dos agroquímicos, com 13\%, os cosméticos, com 4,8\%, os gases industriais, com $2 \%$, e outros diversos, com $11,6 \%$, ratearam o restante dos recursos. Trata-se novamente de alta centralização na catalisação por parte de poucos atores e agentes envolvidos.

Prevalecendo, nesses casos, os dois argumentos-chave salientados anteriormente, é possível lançar outras duas novas linhas centrais de raciocínio: C) Se o argumento (A) anterior for verdadeiro, deve haver critérios básicos que garantam, para apenas uma empresa, a disponibilização de volumes colossais de recursos pela agência do governo; ou D) se for válido o argumento (B), por sua vez, é difícil comprovar que "polímeros" seja o gênero industrial mais dinâmico da indústria química e que justifique tamanha demanda por recursos. Sugere-se a leitura de Gutierrez (1987) e Erber (1997). De qualquer modo (A), (B), (C) e (D) são quatro argumentos polarizados que podem sugerir diversas combinações de leitura.

Finalmente, para fechar a exposição dos dados, apresenta-se um quadro com a Figura 5 onde se demonstra a distribuição dos recursos no território brasileiro por estados da federação. Verifica-se que há uma seletividade na localização dos recursos, sobretudo direcionados ao estado da Bahia, onde se concentram importantes complexos produtivos dos químicos e dos pneus no Brasil. Tanto o polo petroquímico quanto o produtor de borracha, estão localizados em Camaçari, BA, o que pode justificar a drenagem dos expedientes.

É destacável, de qualquer modo, a desigualdade na pulverização dos recursos. Isso ocorre devido aos centros regionais especializados, que exercem pressões econômicas e seletivas na distribuição dos financiamentos. Os estados do Centro-Oeste, por exemplo, concorrem por grande parte dos recursos dos agroquímicos, ao lado do Paraná. São Paulo, como centro dinâmico do País, justifica uma diversificação na demanda e na distribuição. O Rio Grande do Sul, com o polo petroquímico de Triunfo, também aparece como um ímã para os financiamentos. Para Santa Catarina, praticamente $100 \%$ estão articulados ao segmento dos plásticos, com exceção para três aportes no gênero de tintas, motores e gases industriais. 


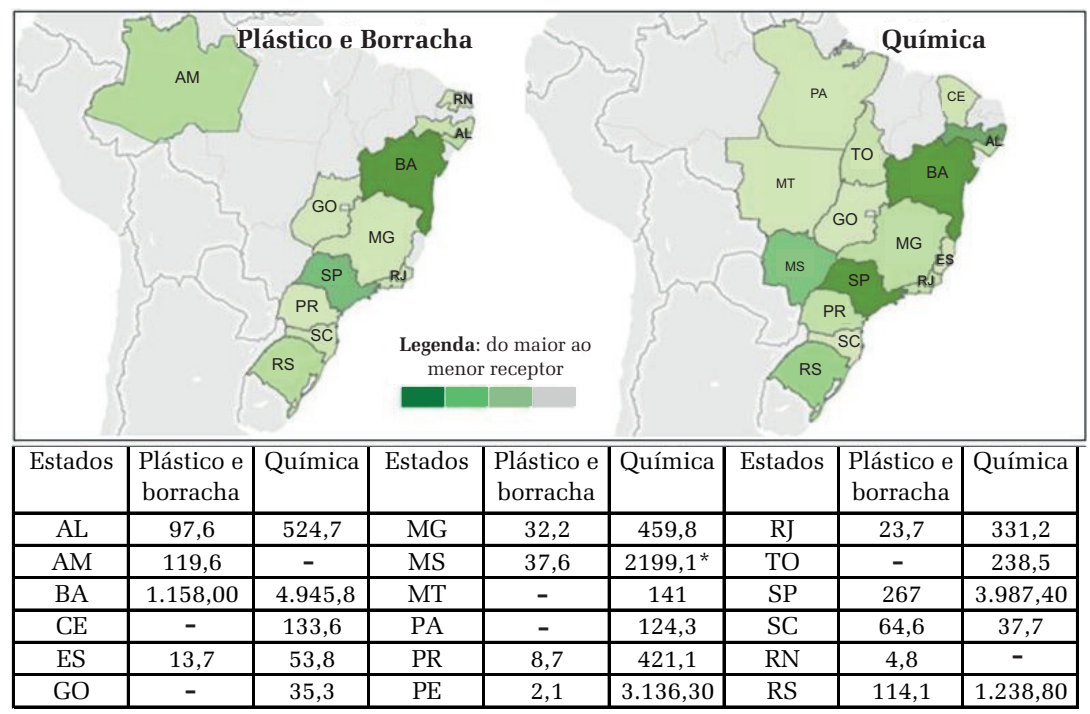

Figura 5 - Distribuição de recursos do BNDES para as indústrias do plástico e borracha e para a indústria química por estado da federação entre 2003 e 2015 (em mil reais) ${ }^{8}$ Fonte: Brasil (2016); Organização do autor.

As empresas, as justificativas e a localização dos recursos

Neste segundo item serão apresentados os dados dos aportes do BNDES numa aproximação com as empresas contempladas, selecionadas conforme já se vem praticando, ou seja, por gênero industrial. Os gêneros explorados em sequência serão: pneus, embalagens e construção civil, pelo lado da indústria do plástico e da borracha, responsáveis por 95\% dos financiamentos. Posteriormente: polímeros, agroquímicos e cosméticos, que, do lado da indústria química, obtiveram 86\% dos recursos. Será explorada a localização, juntamente com os principais projetos de utilização por parte das empresas receptoras.

Indústrias do plástico e da borracha

\section{Pneus}

Anteriormente havia sido destacado, que o gênero industrial dos pneus no Brasil é dominado basicamente por três grupos empresariais, 
todos altamente capacitados para a catalisação dos investimentos. Os três grupos restringem-se à italiana Pirelli ${ }^{9}$, fundada em 1872 e com atuação no Brasil desde 1920; a alemã Continental ${ }^{10}$, fundada em 1871, mas apenas em 2006 com fábrica em solo brasileiro; e a americana Bridgestone ${ }^{11}$, fundada em 1900, com fábrica em Santo André, SP, desde 1939. É impossível afirmá-las entre as "grandes campeãs" por não serem nacionais, porém o volume de capital disponibilizado foi generoso. Demonstra-se na Figura 6 a distribuição de recursos entre as empresas.

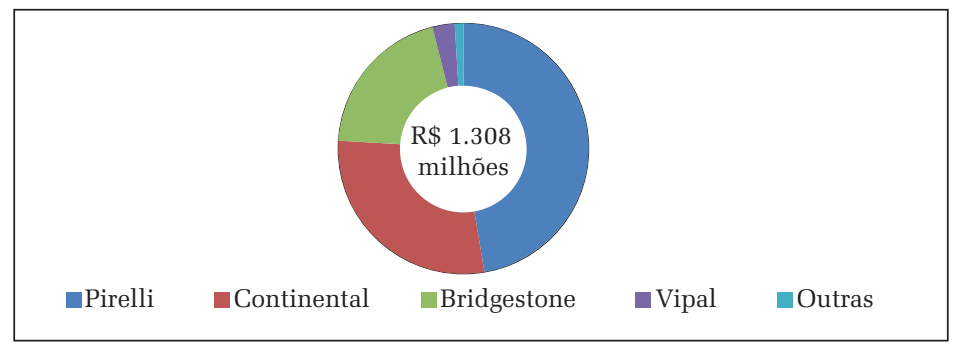

Figura 6 - Distribuição dos aportes do BNDES para o gênero industrial dos pneus por empresas receptoras entre 2003 e 2015

Fonte: Brasil (2016). Organização do autor.

Na descrição dos projetos da Pirelli, o primeiro aporte foi recebido em março de 2002, com o fim de expandir a unidade produtiva do grupo, localizada em Camaçari, BA. Depois disso, entre 2007 e 2014, foram outros sete projetos financiados com a justificativa de modernizar as unidades produtivas da Bahia, do Rio Grande do Sul e de Minas Gerais, ou em apoio aos laboratórios de engenharia nos municípios de Santo André e Sumaré, SP. O grupo Continental, por sua vez, privilegiou-se em março de 2006 na instalação de uma unidade em Camaçari, BA; seguido de outros dois aportes em 2012 e 2013 para ampliação da capacidade produtiva da mesma planta. A Bridgestone foi financiada em apenas um projeto no ano de 2007, para a implantação de nova unidade, também em Camaçari, BA.

\section{Embalagens}

O caso das embalagens parece um pouco mais complexo se comparado ao dos pneus, principalmente pela diversificação na distribuição 
dos recursos e do menor valor, em média, por empresa. No Brasil, soma-se um universo de cerca de 1.800 produtoras de embalagens, em suas maiorias, pequenas e médias alocadas principalmente nos estados da Região Sul e em São Paulo. Trata-se de um mercado concorrencial que cresceu aceleradamente nos últimos 15 anos, portanto, estimulou a competição na captação dos fundos (Schlickmann, 2015).

Sob a guarida do BNDES, foram levantados 25 projetos, distribuídos por 18 empresas, entre as quais algumas decretaram falência ou se fundiram, mas a grande parte expandiu as funções desde o recebimento dos financiamentos. Por se tratar de muitas empresas, serão elencadas as mais catalisadoras e, no âmbito geral, apresenta-se a Figura 7.

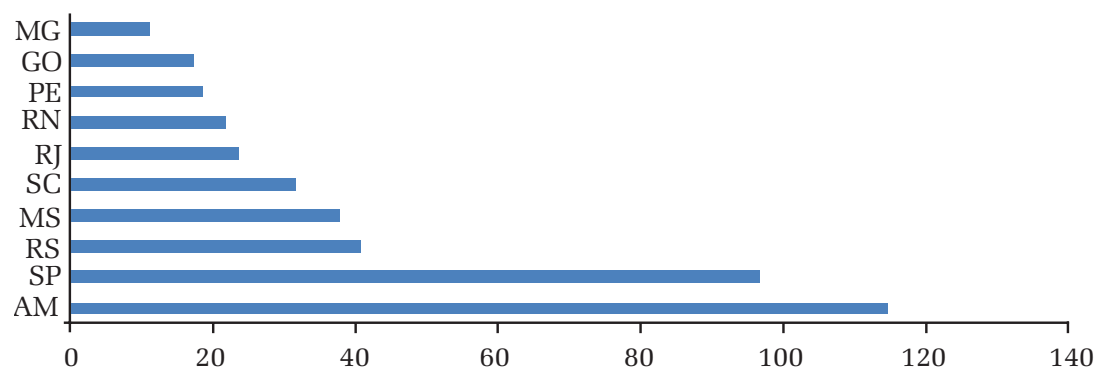

Figura 7 - Aporte do BNDES para o gênero industrial das embalagens por estado da federação entre 2003 e 2015 (em mil reais)

Fonte: Brasil (2016). Organização do autor.

Importa chamar a atenção para a relativização dos dados. Primeiramente, no estado do Amazonas, apenas a empresa Videolar recebeu dois financiamentos para implantação de uma nova unidade de última geração na produção de rótulos. Caso semelhante à empresa Polo, do Rio Grande do Sul, responsável pela totalidade de recursos para aquele estado, utilizados na implantação de uma unidade de vanguarda na produção de embalagens e filmes. A empresa Emplal, hoje Bemis Company, de Mato Grosso do Sul, é um caso idêntico. Nos demais estados, os recursos são diluídos para diversas empresas e as justificativas são: capital de giro, modernização e geração de nova capacidade. Em Santa Catarina, todos os recursos foram destinados para Biguaçu e distribuídos entre três empresas: Plasc, Inplac e Mondiana. 


\section{Construção civil}

O gênero industrial da construção civil, assim como o dos pneus, é concentrado em três grupos empresariais tradicionais que dominam a produção e o mercado nacional. São elas: Tigre; Amanco e Krona, todas com sede em Joinville, SC, porém com plantas industriais e investimentos espalhados pelo país e pelo mundo. A Amanco, porém, pertence ao grupo mexicano Mexiquem e não recebeu nenhum aporte do BNDES no tempo que abrange este artigo. Portanto, as duas catarinenses centralizaram $89,5 \%$ dos fundos direcionados para a construção civil dentro da indústria do plástico, gênero que se restringe a gama de tubos, conexões e acessórios. Essas informações estão representadas na Figura 8.

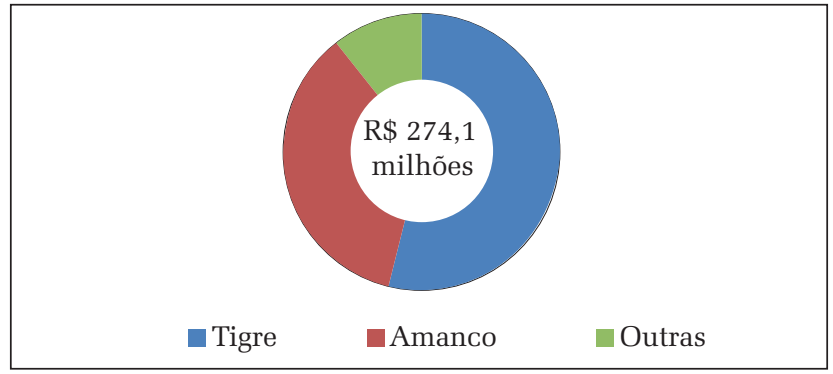

Figura 8 - Distribuição dos aportes do BNDES para o gênero industrial da construção civil por empresa receptora entre 2003 e 2015 Fonte: Brasil (2016). Organização do autor.

Em relação aos recebimentos da empresa Tigre, observa-se uma tendência à implantação de projetos modernizadores de processos internos das fábricas, tais como segurança no trabalho e gestão de pessoas. Contudo, apesar de a empresa despontar como uma grande "campeã nacional", o primeiro aporte recebido data somente de junho de 2012, tendo sido direcionado para o aumento da capacidade produtiva. Depois disso foram outros quatro projetos contemplados. A Krona também acessa tardiamente o BNDES, apenas em junho de 2011, e o fez para construir uma nova unidade produtiva em Marechal Deodoro, AL. Posteriormente a essa data foram outros três projetos, todos destinados à ampliação da unidade produtiva alagoana. As outras quatro empresas aportadas transitam no mercado marginal da construção civil. 


\section{Indústria química}

\section{Polímeros}

Diante da conjuntura que se desenrolou em torno da operação Lava Jato e da conexão com o Grupo Odebrecht/Braskem, as operações de financiamentos que consolidaram a gigante participação do Brasil no mercado de polímeros passam por algumas contestações, sobretudo devido ao volume dos recebimentos. O fato é que a Braskem foi responsável por investir mais da metade do capital disponibilizado pelo BNDES para todo o conjunto da indústria química.

Outro elemento razoável de dúvidas é em relação ao domínio do mercado de resinas termoplásticas populares: polietileno, polipropileno e PVC, que representa baixo conteúdo técnico, baixo valor agregado e tecnologia amplamente difundida (Gutierrez, 1987). Há ainda o agravante da monopolização do mercado nacional das resinas e a comercialização com sobrepreço de 23\% em relação ao mercado internacional (Schlickmann, 2015).

Como apresentado na Figura 4, o grupo baiano tomou conta de mais de 75\% dos investimentos direcionados para o gênero dos polímeros na indústria química. O interessante é que, segundo o site da empresa ${ }^{12}$, sua data de fundação é agosto de 2002, porém consta o primeiro aporte financeiro em maio do mesmo ano, três meses antes da oficialização. Posteriormente a essa data foram mais 25 financiamentos diretos, além de outros seis direcionados a grupos empresariais que a Braskem veio a adquirir. As justificativas são diversas, complexas e técnicas, dentre as quais: construção de novas unidades, implantação de armazéns, modernização de plantas, plano de investimentos, projetos de pesquisas e paradas programadas nas unidades de produção. Poder-se-ia afirmar que o grupo baiano é o expoente máximo da criação e manipulação de uma "campeã nacional".

\section{Agroquímicos}

Como os polímeros centralizaram enorme parte dos investimentos, apenas 13\% do total direcionado à indústria química, voltou-se aos agroquímicos. Diferentemente do mercado monopólico por um grupo nacional das resinas, os agroquímicos vão dos grupos internacionais como a Bunge, aos nacionais como a Oxiteno. Há também algumas empresas químicas de menor porte em área de pesquisa e produção de produtos agropecuários diversos. 
O mercado nesse caso é segmentado, ou seja, dependendo da especialização da empresa, observa-se maior influência concorrencial. Um exemplo são os biocombustíveis, pois inúmeros competidores pesquisam e concorrem pelo mercado. Os fertilizantes, todavia, são praticamente dominados pela Vale Fértil e pela Iharabras. Segue-se a Figura 9 com as cinco principais empresas receptoras dos investimentos.

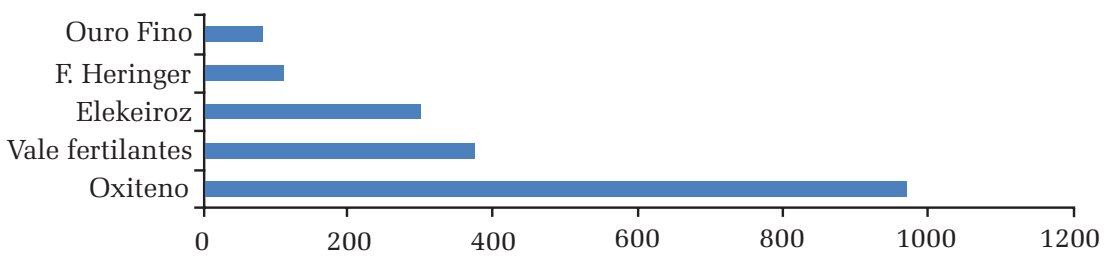

Figura 9 - Os cinco maiores receptores de aportes financeiros do BNDES para 0 gênero dos agroquímicos entre 2003 e 2015 (em mil reais)

Fonte: Brasil (2016). Organização do autor.

Na Figura 9 nota-se a preponderância do Grupo Oxiteno. É interessante que a empresa enquadra-se entre as "potenciais campeãs nacionais", o que, por si só, representou um argumento para os caminhos dos aportes. Desde abril de 2002 até agosto de 2015 foram dezoito projetos financiados com o contexto da modernização das plantas, os planos de investimentos e a implantação de novas unidades. A Elekeiroz foi financiada em oito projetos, embasados nos mesmos argumentos. A Vale Fertilizantes obteve dois aportes, em 2009 e 2010: um para ampliação dos armazéns e outro para a expansão da produção de fertilizantes. A Ouro Fino e a F. Heringer acionaram apenas uma vez o banco para a implantação de unidades produtivas de defensivos agrícolas e de fertilizantes. Mais de 90\% do montante desses recursos foram alocados com alto domínio no estado de São Paulo, seguido por Minas Gerias, Bahia, Goiás e Rio Grande do Sul.

\section{Cosméticos}

O gênero industrial dos cosméticos, conforme inúmeras reportagens que podem ser consultadas na internet, bem como na publicação da Associação Brasileira de Higiene Pessoal, Perfumaria e Cosmético 
(ABIHPEC), é um dos que mais ascenderam no período recente. Nos últimos 18 anos representou um acumulado de 436,3\%, o que significa crescimento médio de $24,2 \%$ ao ano, sendo o Brasil o segundo consumidor mundial de produtos relacionados à estética e à beleza (ABIHPEC, 2014).

Trata-se de um gênero industrial concentrado em poucas empresas, tanto em relação à produção quanto no processo de comercialização, que é racionado em todo o País pelos milhares consultores de vendas, vinculados aos grupos empresariais. Trata-se do envolvimento de uma cadeia de negócios gigantesca, que reservou para o gênero dos cosméticos, 4,8\% dos recursos disponibilizados para a indústria química. Mais detalhes a esse respeito na Figura 10.

Figura 10 - Distribuição dos aportes do BNDES para o gênero industrial dos cosméticos por empresa receptora entre 2003 e 2015

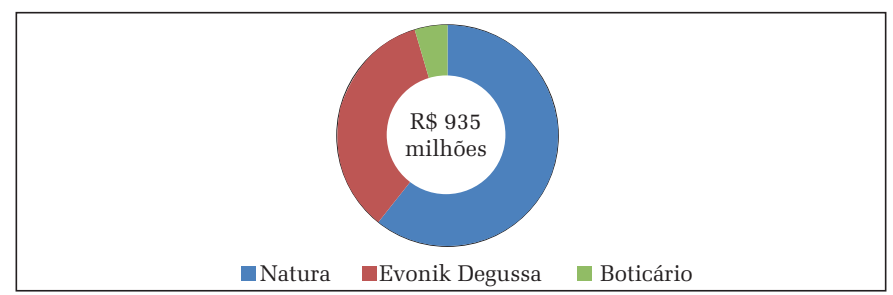

Fonte: Brasil (2016). Organização do autor.

As empresas Natura e Boticário competem diretamente pelo mercado brasileiro e internacional. A Evonik Degussa ${ }^{13}$, por sua vez, é uma diversificada empresa alemã fornecedora de químicos em geral: cosméticos, pneus, agroalimentos, bioenergia, entre outros. Os recursos recebidos são distribuídos para todos esses gêneros, o que dificulta a especificação. Porém, segundo as descrições do BNDES (Brasil, 2016), a empresa direcionou seu penúltimo financiamento recebido em 2013, para a instalação de uma fábrica de cosméticos no estado do Paraná; outros quatro projetos foram para expansão da capacidade produtiva instalada.

A Natura, no entanto, concorreu entre as "campeãs nacionais". Nota-se isso pelo volume de capital recebido, superando $60 \%$ do total destinado ao gênero, sendo treze vezes superior ao que foi demandado pela sua maior concorrente. No total, são quatorze projetos financiados entre 2005 e 2015, todos destinados ao estado de São Paulo, com os objetivos 
de cumprir os planos de investimentos, ampliar armazéns, integrar as equipes de consultores e modernizar as fábricas. Coube exceção a dois projetos alocados no estado do Pará em 2011, para a construção do Ecoparque Natura ${ }^{14}$. A empresa Boticário, finalmente, foi contemplada com dois investimentos de pequena monta: um em 2008, para ampliação e modernização do complexo industrial localizado no estado do Paraná, e outro em 2011, para a ampliação do centro de pesquisa localizado no estado do Rio de Janeiro.

\section{Considerações finais}

Em síntese, a partir do universo dos capitais disponibilizados pelo BNDES para a indústria de plástico e borracha e para a indústria química brasileira, chegou-se ao nível da empresa, da localização dos aportes e dos objetivos dos investimentos, dentro dos gêneros industriais específicos da produção. Com esse exercício, finalmente, foi possível verificar ao menos três características basilares do processo de fomento governamental aplicado nos últimos treze anos no Brasil: 1) Um número restrito de grupos empresariais recebeu uma enxurrada de recursos, com destaque em seus gêneros industriais: Pirelli e Continental (pneus); Tigre e Krona (construção civil); Braskem (polímeros); Oxiteno (agroquímicos); e Natura e Evonik Degussa (cosméticos); 2) Em cada gênero industrial a ampliação do fomento contribuiu para a oligopolização ou para a monopolização do mercado; e 3) Permaneceu rígida a distribuição dos recursos para as regiões especializadas em suas atividades econômicas tradicionais, ou seja, o banco estatal não propiciou a difusão das atividades econômicas no território.

Finalmente, diante da crise econômica que se abateu no País e do esforço despendido pelo BNDES para a alocação dos altos volumes dos recursos, permanecem importantes questões:

a) Adotou-se uma política de tipo "campeãs nacionais" para financiamento da industrialização nos últimos anos?

b) É possível prestar contas dessas políticas de financiamento?

c) Quais os critérios técnicos que indicam, por exemplo, que a maior eficiência econômica na indústria de químicos no Brasil está no gênero de polímeros e, especificamente, na empresa Braskem, assim como noutros gêneros e empresas?

d) Qual seria a relação econômica entre a quantidade e a qualidade desses investimentos e suas economias de aglomeração? 
Parece, enfim, que o ônus da implantação do ideário não será pago pelos crentes intervencionistas. O Brasil certamente está maior do que antes. Não vejo, todavia, pelo lado econômico, a possibilidade de se aludir quando foi esse antes, nem em quais sentidos o País está maior. Inúmeras perspectivas e abordagens são necessárias para reavaliar e reconstruir nosso passado. Entendo que a geografia econômica pode desempenhar importante papel questionador e debatedor nessa tarefa.

Agradecimentos

O autor agradece o auxílio financeiro do CNPq (Bolsa de doutorado - GD) vigente de Março de 2014 a Fevereiro de 2018.

\section{Notas}

1 Sugere-se a leitura de Coutinho e Sarti (2003), que lançam um processo de diagnóstico das cadeias produtivas e indústrias com potencial eficiência competitiva. Parece o início de uma eleição de indústria e gêneros industriais a serem financiados, além da leitura de Coutinho (2014), exposta em um emblemático título para o Fórum Nacional do BNDES. Título do fórum: Rumo ao Brasil desenvolvido: Uma revolução industrial - a maior desde 1790.

2 Disponível em: <http://www.bndes.gov.br/SiteBNDES/bndes/bndes_pt/ Institucional/BNDES_Transparente/Consulta_as_operacoes_do_BNDES/index. html>. Acesso em 24 jun. 2016.

\section{Em andamento.}

4 Leio a social democracia no aspecto da grande política, conforme Bresser-Pereira (2015). Trata-se da alternativa de organização política possível em contraposição ao liberalismo amplo. Ao transitar da origem ideológica socialista para uma forma de governo mais moderada, a ideologia petista metamorfoseia-se numa social democracia à esquerda se comparada à social democracia peessedebista sob liderança de Fernando Henrique Cardoso e José Serra. (Samuels, 2004).

5 Optou-se pela preservação da Figura 1 ao não inserir os dados totais dos desembolsos do BNDES para o universo das atividades econômicas. Isso porque, metodologicamente ao disponibilizar uma terceira série de dados de volumes 
relativamente elevados, o gráfico tornar-se-ia inelegível devido ao montante bilionário não compatível com a simplificação na casa dos milhões, aplicáveis aos químicos, plásticos e borrachas. Para satisfazer a comparação, destaca-se que os investimentos totais giraram respectivamente em 1995 na casa dos $\mathrm{R} \$$ 7.098 milhões; em 2002 foram R\$ 37.419 milhões, atingindo o pico em 2013 com $\mathrm{R} \$ 190.419$ milhões e fechando 2015 em R\$ 135.942 milhões. $O$ total de aporte no pico em 2013 evidencia uma quantia 56 vezes maior que a parcela recebida pela indústria química e 77,5 vezes maior ao que coube a indústria do plástico e borracha. Dados em Brasil (2016).

6 Disponível em: <http://www.bndes.gov.br/SiteBNDES/bndes/bndes_pt/ Institucional/Sala_de_Imprensa/Noticias/2010/industria/20100611_BNDES Proplastico.html>. Acesso em: 24 jun. 2016.

7 É importante ressaltar, diante esses dados, a exclusão de um único aporte para a Petrobrás referente à indústria química no valor de 2,2 milhões de reais, que não foram computados na Figura 2.

8 Asterisco em Mato Grosso do Sul referente ao único investimento em químicos que consta em nome da Petrobras que foi desconsiderado neste artigo.

9 Disponível: <https://www.pirelli.com/tyres/pt-br/index>. Acesso em: 24 jun,2016.

10 Disponível em: <http://www.continental-corporation.com/www/portal_br_ pt/>. Acesso em: 24 de jun. 2016.

11 Disponível em: <http://www.bridgestone.com.br/institucional>. Acesso em: 24 jun. 2016.

12 Disponível em: <https://www.braskem.com.br/perfil>. Acesso em: 24 jun.2016.

13 Disponível em: <http://corporate.evonik.com.br/region/central-south-america/ pt/Pages/default.aspx>. Acesso em: 24 jun.2016.

14 Disponível em: <http://www.natura.com.br/sites/default/files/static/ relatorio/8_2_sociobiodiversidade_2.html>. Acesso em: 24 jun.2016. 


\section{Referências}

ABIHPEC. Panorama do setor de HPPC. São Paulo: ABIHPEC, 2014. 14 p.

ALMEIDA, M.; OLIVEIRA, R. L. de; SCHNEIDER, B. R. Política industrial e empresas estatais no Brasil: BNDES e Petrobrás. Brasília, Rio de Janeiro: IPEA, 2014. 60 p.

BRASIL. Banco Nacional do Desenvolvimento Econômico e Social. Portal da transparência: consulta a financiamentos. Rio de Janeiro, RJ, 2016. Disponível em: <http://www.bndes.gov.br/SiteBNDES/bndes/bndes_pt/Institucional/BNDES

Transparente/Consulta_as_operacoes_do_BNDES/index.html>. Acesso em: $2 \overline{4}$ jun.2016.

BRESSER-PEREIRA. L. C. A construção política do Brasil: Sociedade e Estado desde a independência. 2.ed. São Paulo: Editora 34; 2015. 461 p.

COUTINHO, L. Desafios para o crescimento sustentado. In: VELLOSO, J. P. dos R. et al. (Coord.). Visões do desenvolvimento brasileiro e a nova revolução industrial: a maior desde 1790. Rio de Janeiro: Fórum Nacional, 2014. p. 17-25.

COUTINHO, L.; SARTI, F.. A política industrial e a retomada do desenvolvimento. In: LAPLANE, H.; COUTINHO, L.; HIRATUKA, C. (Org.). Internacionalização e desenvolvimento da indústria brasileira. São Paulo: Editora Unesp, 2003. p. 329-347.

ERBER, F. Desarrollo y reestruturación de la petroquímica brasileña. In: CHUDNOVSKY, D.; LÓPEZ, A. (Org.). Auge y ocaso del capitalismo asistido: la industria petroquímica latino-americana. Buenos Aires: Alianza; 1997. p. 159-226.

GUTIERREZ, R. Maduración tecnológica y perspectivas de la industria petroquímica mundial. Comércio Exterior: México, v. 37, n. 12, p. 994-1005, 1987.

KEYNES, J. M. A teoria geral do emprego, do juro e da moeda. São Paulo: Abril Cultural, 1983. 333 p.

RANGEL, I. Ciclo, tecnologia e crescimento. Rio de Janeiro: Civilização brasileira; 1982. $186 \mathrm{p}$.

SAMUELS, D. From socialism to social democracy: party organization and the transformation of the Worker's Party in Brazil. Comparative Political Studies, v. 37, n. 9, nov. 2004, p. 999-1024, 2004.

SCHLICKMANN, P. H. A produção de produtos plásticos no Brasil: Uma perspectiva histórica e geoeconômica. Estudos Geográficos, Rio Claro, SP, n. 13, v. 2, p. 57- 76, jul./dez. 2015.

SINGER, A. Os sentidos do lulismo: reforma gradual e pacto conservador. São Paulo: Companhia das Letras, 2012. 276 p.

VELASCO JÚNIOR, L. Documento histórico: A privatização no sistema BNDES. Revista do BNDES, Rio de Janeiro, n. 33, p. 307-382, 2010. 
Paulo Henrique Schlickmann - Licenciado em geografia pela Universidade do Sul de Santa Catarina. Mestrado em geografia pela Universidade Federal de Santa Catarina. Atualmente é estudante de doutorado em geografia na Universidade Federal de Santa Catarina.

Recebido para publicação em 02 de agosto de 2016

Aceito para publicação em 18 de setembro de 2016 